\title{
Dantrolene and lymphocytic lymphoma
}

\author{
H. H. WAN \\ M.B., M.Sc., M.R.C.P.
}

J. S. TUCKER

M.B., M.R.C.P.

University Hospital of South Manchester, Manchester M20 8LR

\begin{abstract}
Summary
A patient is reported who was on prolonged treatment with dantrolene for spastic paraplegia; he developed a malignant lymphoma which led to his death.

\section{Introduction}

Dantrolene is a skeletal muscle relaxant with a direct action on skeletal muscle. Chemically it is a hydantoin derivative (1-[(5-arylfurfurylidene)amino] hydantoin). The drug has been available in the U.K. for general use since June 1976. As with any new drug, the long-term safety of dantrolene has not been established. The development of lymphoproliferative disorders in association with another hydantoin derivative, phenytoin (diphenylhydantoin), has been well documented (Saltzstein and Ackerman, 1959; Hyman and Sommers, 1966; Gams, Neal and Conrad, 1968; Anthony, 1970). Despite the similarity in chemical structure of this new drug dantrolene with that of phenytoin, lymphoproliferative disorder has not until now been recorded. The authors report a case of lymphocytic lymphoma associated with prolonged dantrolene therapy.
\end{abstract}

\section{Case report}

A 64-year-old man had a history of progressive spastic paraplegia over 10 years. Investigations, including CSF examination and myelogram performed 8 years previously had not established the underlying lesion, but demyelinating disease was suspected. Clinical examination in 1972 had shown a marked global weakness of both legs with hyperreflexia and extensor plantar responses. By 1973 he became wheelchair-bound and complained of increasingly troublesome muscle spasm. Maturity onset diabetes mellitus was also diagnosed at that time and treated with a $120-\mathrm{g}$ carbohydrate diet. In November 1973, treatment with baclofen was commenced and the dosage increased to $120 \mathrm{mg}$ daily in divided doses with little relief of spasticity. This drug was withdrawn in stages in March 1975 and treatment with dantrolene commenced. The dosage was gradually increased to $600 \mathrm{mg}$ daily in divided doses, with significant relief of muscle spasm. From June 1974, he had also been given intermittent courses of Moduretic (amiloride hydrochlorothiazide) one tablet daily for mild congestive cardiac failure. In June 1977, tolbutamide $500 \mathrm{mg}$ thrice daily was prescribed for his now symptomatic diabetes mellitus, and satisfactory control was regained. Dantrolene was continued in the same dosage and throughout his treatment with this drug haematological and biochemical profiles remained normal, and his general condition remained satisfactory. In January 1978, his haemoglobin was $14.4 \mathrm{~g} / \mathrm{dl}$ with normal indices and WBC $7 \cdot 9 \times 10^{9} / 1$. In March 1978 he was admitted to hospital with vomiting and moderate glycosuria. There were signs of consolidation in the lower lobe of the left lung but no superficial lymphnode enlargement and the liver and spleen were not palpable. Blood glucose was slightly raised at 12.6 $\mathrm{mmol} / \mathrm{l}$ and $\mathrm{Hb}$ had fallen to $8 \cdot 1 \mathrm{~g} / \mathrm{dl}$ with normochromia and normocytosis. The WBC was $6.0 \times 10^{9} / 1$ with $50 \%$ lymphocytes. Sternal marrow examination showed a marked increase in cellularity, most of the cells being of the lymphoid series and consisting mainly of mature lymphocytes. Despite treatment of his pneumonia, he died shortly afterwards. At post-mortem examination confluent bronchopneumonia of the left lung was confirmed. No macroscopic abnormalities were found on examination of the CNS. On histological examination, the liver showed an infiltration of the portal tracts by lymphoid cells, predominantly mature lymphocytes; some of which were present in the sinuses. Bone marrow section confirmed the findings on sternal marrow examination. The overall appearances were those of a moderately well differentiated lymphocytic lymphoma.

\section{Discussion}

The development of lymphadenopathy as one of the less common side effects of phenytoin has long been recognized (Saltzstein and Ackerman, 1959). Although originally regarded as a benign complication of hydantoin therapy, reversible on withdrawal of the drug, it was later clear that the use of this anticonvulsant could be associated with the development of fatal malignant lymphoma (Hyman and 
Sommers, 1966; Gams et al., 1968; Anthony, 1970). The evidence in the present case suggests that the patient developed a lymphoproliferative disorder which led to his death some 3 years after starting treatment with dantrolene. Of the other drugs involved in the treatment of this patient, tolbutamide is not known to induce lympho-proliferative disorders, although haematological reactions (leucopenia, agranulocytosis, thrombocytopenia, pancytopenia and haemolytic anaemia) have been reported (Goodman and Gilman, 1975). Similarly, Moduretic has not been implicated in causing lymphoreticular malignancies. Dosage up to $800 \mathrm{mg}$ dantrolene daily is recommended for occasional patients to achieve a satisfactory response. However, on the evidence of this case, the authors suggest that prolonged treatment with this drug in relatively large dosage must be undertaken with extremeڤ caution.

\section{References}

ANThoNy, J.J. (1970) Malignant lymphoma associated with hydantoin drugs. Archives of Neurology, 22, 450.

Gams, R.A., Neal, J.A. \& ConRaD, F.G. (1968) Hydantoin-든 induced pseudo-pseudolymphoma. Annals of Internal Medicine, 69, 557.

Goodman, L.S. \& Gilman, A. (1975) The Pharmacological Basis of Therapeutics, 5th edn, p. 1521. MacMillan Publishing Co., Inc., New York.

Hyman, G.A. \& Sommers, S.C. (1966) The development of $\overrightarrow{0}$ Hodgkin's disease and lymphoma during anticonvulsant $\overrightarrow{ }$ therapy. Blood, 28, 416.

Saltzstein, S.L. \& ACKerman, L.V. (1959) Lymphadeno-pathy induced by anticonvulsant drugs and mimicking clinically and pathologically malignant lymphomas. 3 Cancer, 12, 164. 